\title{
BIM Integration Possibilities in Different Study Cycles of Architecture Study Programme
}

\section{Aušra Mlinkauskienė*, Laura Jankauskaitė-Jurevičienė}

Kaunas University of Technology, Faculty of Civil Engineering and Architecture Studentu st. 48, LT-51367 Kaunas, Lithuania

\section{Per Christensen}

VIA Architectural Technology and Construction Management Chr. M. Østergaards Vej 4, DK - 8700 Horsens, Demmark

\section{Luca Finocchiaro, Gabriele Lobaccaro}

Department of Architecture and Technology, Norwegian University of Science and Technology, Alfred Getz vei 3 _ NO 7491 Trondheim, Norway

*Corresponding author: ausra.mlinkauskiene@ktu.lt

\section{$\Gamma$} Crossef http://dx.doi.org/10.5755/j01.sace.26.1.22393

European countries are developing or implementing policies that promote or require the use of information modelling in the architecture, engineering, construction and manufacture sectors. The integration of Building Information Modelling (BIM) to these sectors includes social, economic, political, legal and other aspects. This is why the implementation of BIM requires an integrated and broad approach that includes not only the BIM implementation and development strategy in designing companies but also in the field of education and professional training. The article discusses the potential of integrating BIM in different study programs and the possibilities of international cooperation in interdisciplinary BIM projects. The different levels of BIM will be explored in connection to different curricula. Particular attention is paid to the compatibility and applicability of design and innovative technology solutions using BIM methodology and the development of co-operation between higher education institutions in the Nordic region [1].

The aim of this paper is to carry out a comparative analysis and present the integration model of Building Information Modeling (BIM) into the Architecture programmes in different study cycles based on the example of Nordic countries.

Objectives:

_ To provide BIM use opportunities in 3 years Bachelor level based on Engineeering architecture study programme of VIA University College;

_ To provide BIM use opportunities in 5 years Integrated studies based on Architecture studies programme of Kaunas University of Technology;

_ To provide BIM use opportunities in the 2 years Master of Science program in Sustainable Architecture at the Norwegian University of Science and Technology;

_ To perform comparative analysis between different countries and different study cycles;

_ To provide a possible model for integration of the international BIM project in different study cycles.

Keywords: Building information modelling (BIM), architecture studies.

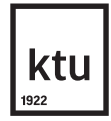

Journal of Sustainable Architecture and Civil Engineering Vol. 1 / No. 26 / 2020 pp. $5-17$ DOI 10.5755/j01.sace.26.1.22393 
Introduction

\section{BIM Use}

Opportunities in Bachelor Studies
Architecture studies shall be balanced between the theoretical and practical aspects of architectural training and shall ensure the acquisition of: an ability to create architectural designs that satisfy both aesthetic and technical requirements; an adequate knowledge of the history and theories of architecture and the related arts, technologies and human sciences; a knowledge of the fine arts as an influence on the quality of architectural design; an adequate knowledge of urban design, planning and the skills involved in the planning process; an understanding of the relationship between people and buildings, and between buildings and their environment, and of the need to relate buildings and the spaces between them to human need and scale; an understanding of the profession of architecture and the role of the architect in society, in particular in preparing briefs that take account of social factors; an understanding of the methods of investigation and preparation of the brief for a design project; an understanding of the structural design, constructional and engineering problems associated with building design; an adequate knowledge of the physical problems and technologies and of the function of buildings so as to provide them with internal conditions of comfort and protection against the climate; the necessary design skills to meet building users requirements within the constraints imposed by cost factors and building regulations; an adequate knowledge of the industries, organisations and procedures involved in translating design concepts into buildings and integrating plans into overall planning [2].

Nowadays it is very important for an architect to adapt today's technologies and to be able to work in a team with engineering specialties. This is possible to do with BIM technologies.

In this definition, technological processes occupy an important place in architectural studies. Even some of the above are focused on digitization and technological processes: an ability to create architectural designs that meet both aesthetic and technical requirements; an understanding of the structural design, constructional and engineering problems associated with building design; adequate knowledge of the physical problems and technologies and the function of buildings so as to provide them with internal comfort and protection conditions against the climate; necessary design skills to meet building user requirements within the limits imposed by cost factors and building regulations; An adequate knowledge of the industries, organizations and procedures involved in translating design concepts into buildings and integrating plans into general planning.

\section{Architectural Technology and Construction Management Programme of Via University College}

In accordance with the rules for the study programmes, cf. Ministerial Order no. 715 of 7 July 2009 on the professional bachelor programme in Architectural Technology and Construction Management, the Academy Profession Programme in Construction Technology and the Academy Profession Programme in Surveying and Mapping, parts of the discipline-specific contents of the three programmes are common, as illustrated in Fig.1 [3].

The Architectural Technology and Construction Management programme has duration of 31/2 years and is made up of seven semesters totalling 210 ECTS, which are composed of a number of compulsory andelective programme elements, including internship and bachelor project.

The compulsory programme elements are common to all programmes offered in Denmark. However, the individual institution has defined the elective programme elements. A further description of these appears from the common and institution-specific part, respectively.

The Architectural Technology and Construction Management programme is also offered in Danish. The Danish title is Bygningskonstruktøruddannelsen.

The distribution of ECTS points on compulsory and elective programme elements, including internship and bachelor project, is illustrated in the following Fig. 2 [3].

BIM is an integrated approach to digitize the construction process. Throughout the building's lifecycle, from conception to demolition, the digital building models will be the focal point for all con- 

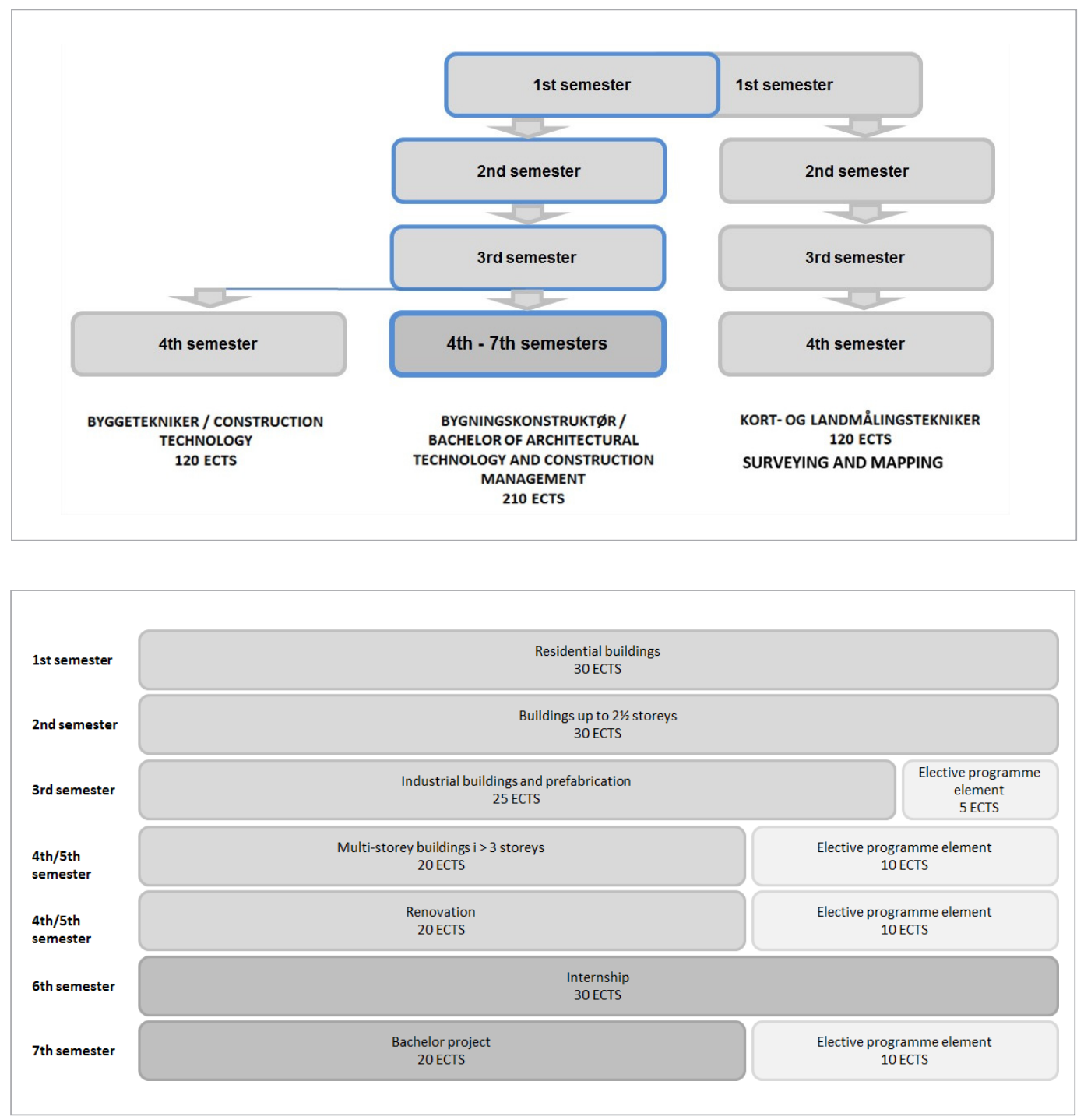

Fig. 2

The compulsory and elective elements of the Architectural Technology and Construction Management programme

struction activities of the project and the cooperation between the different parties. BIM is both a model and a methodology. BIM means closer cooperation between all parties and branching out to each player participating in a project.

The Implementing Network for Digital Construction was formed in 2005 and consists of the 7 largest organizations in the construction industry in Denmark. The network was formed to carry out awareness and implementation of Digital Construction in the construction industry and was until 28.02.2011 responsible for development, content and operation of the portal www.detdigitalebyggeri.dk

The association "bips" took over the operation of the portal First March 2011.

Since the beginning and up until now there have continuously been taken initiatives to meet those, in the legislation, increased demand for digitization, so that the development is also reflected in the classroom.

BIM implementation on the programme is based on BIM guides developed by Pennsylvania State University, with its BIM applications (BIM uses).

There will be variations in relation to teaching depending on the actual location and in relation to the teaching of the Danish and international classes. 
BIM Uses - Progression through the semesters. The progression of BIM uses through the Constructing Architect courses' semesters happens via $\mathbf{5}$ focus areas:

1. Basic modelling and extraction from drawings;

2. Quantity take-offs;

3. Utilization of the properties data, incl. establishment of own properties data;

4. Visualization;

5. Integration with other software applications (hereafter called programs).

\section{BIM Use} Opportunities in 5 Years Integrated Studies

\section{Based On Architecture Studies Programme of Kaunas University of Technology}

Structure of the Architecture Study Programme. The aim of the Architecture study programme, taught at the faculty of Civil Engineering and Architecture of KTU is: to provide the knowledge to understand the socio-cultural and technological content of architecture, to express it through architectural artistic means, to develop the ability to identify and solve architectural problems by applying interdisciplinary knowledge, to develop research and design skills and the ability to visualize architectural solutions.

The duration of the study programme in KTU is five years and it meets the new requirements of the directive. Practical professional work oriented subjects take more than 50 credits of the Architectural design and urban planning programme. This corresponds to the need to strengthen the practical part of preparation of architects, established in the directive, and informally it also meets the requirement to make architecture the component of the studies. So far, this requirement was meet in programmes of other universities of Lithuania by including design and supporting, serving modules. As the programme is taught at the Faculty of Civil Engineering and Architecture, it is beneficial for group work of the future architects and civil engineers.

Base on the presented information it can be stated that the content of Architecture integrated studies provides students with the necessary theoretical knowledge and practical skills, specified in Directive 2013/55/EU of the European Parliament and of the Council of 20 November 2013, as well as programmes of higher education of this field in other countries of the European Union.

The five year Architecture study programme consists of the following parts: 1) design based, 2) research based, 3) practice based, 4) test based (according to students' needs), 5) general required. By the university selected parts study programme consist following parts: 1) general subjects of university studies, 2) subjects of the study field, 3) practice, 4) final degree project, 5) optional subjects (according to students' needs). The total scope of the programme of architectural studies is $300 \mathrm{cr}$., from $15 \mathrm{cr}$. or 5 percent of the entire scope of the study programme is allocated to general university study subjects, $225 \mathrm{cr}$. or 75 percent - to subjects of the study field, practice is $18 \mathrm{cr}$. or 6 percent., and the final degree project consists of $30 \mathrm{cr}$. or 10 percent of the entire scope of the study programme. The optional subjects are given $12 \mathrm{cr}$. or 4 percent of the entire scopes of the study programme. The chronological order of individual subjects of the study programme in the semester is based on the necessity of preparation for studies of that subject. Practical design modules and theoretical, technological modules are placed in accordance with the principle of consistency, starting with improvement of knowledge from simple analysis of architectural object and submission of design proposals - a mono-functional object, and later, obtaining professional knowledge for design of a multifunctional architectural object. During the $7^{\text {th }}$ and $8^{\text {th }}$ semesters students gain knowledge on both the level of static design (architectural), and formation of the environment (urbanistic), and will receive the architect's qualification degree after finishing the final degree project [4].

The programme based on principles of interdisciplinary, creativity and innovation, critical thinking and problem solving ensures adaptation of graduates in the ever-changing and diverse multicultural, technological, social contexts. All of this determines its uniqueness and appeal. 


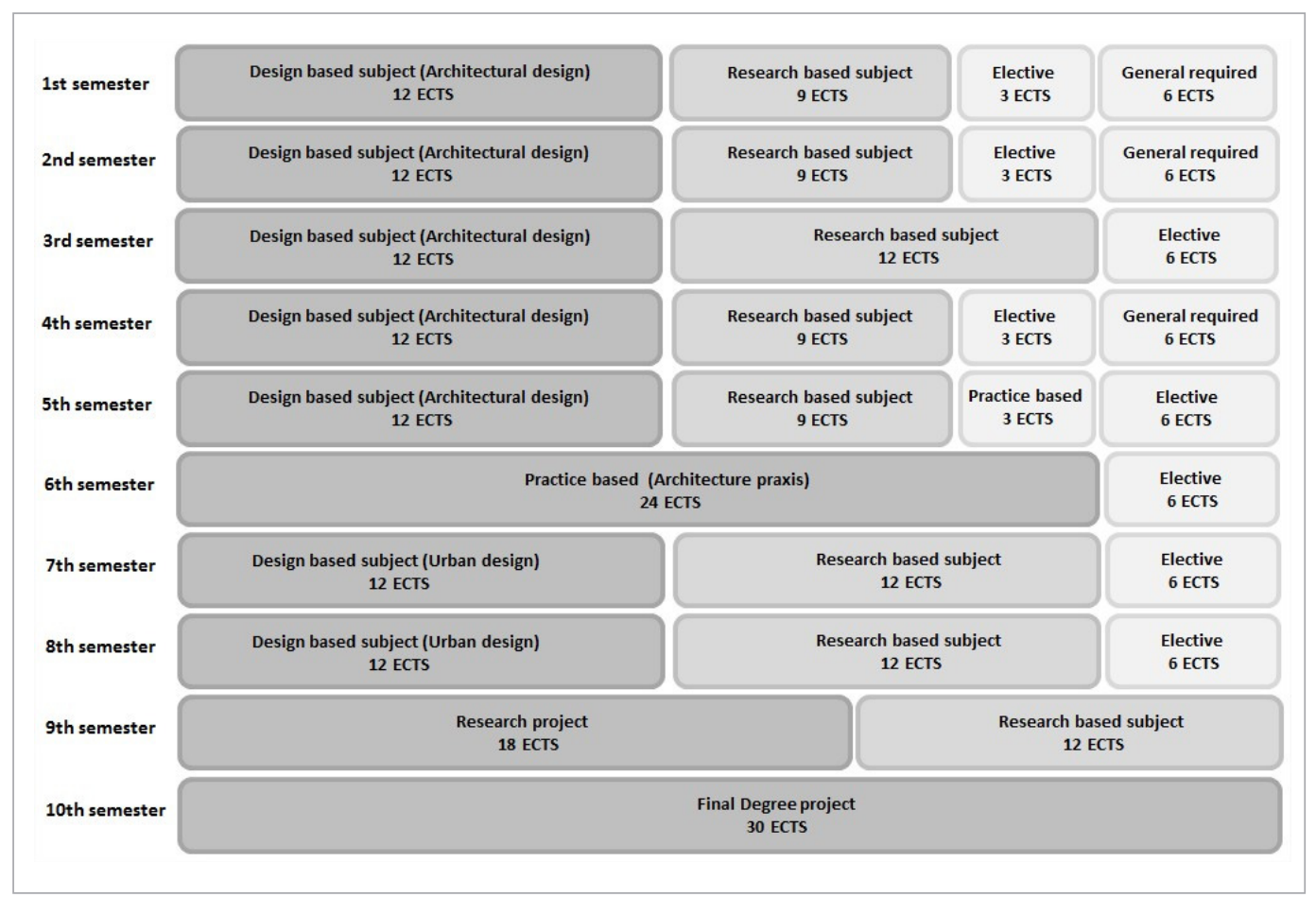

Fig. 3

Structure of the KTU Architectural study programme

The principles of formation of the study programme and its learning outcomes:

- Design and problem tasks oriented environment: the study programme is based on design tasks, the developed critical thinking, problem tasks and other concepts of modern educational sciences. Students are encouraged to work in groups to develop critical thinking, organizational skills and to seek creative solutions to real existing architectural problems and challenges.

- The didactical system of the study programme is based on the approach that the lecturer must only be there for support, helping find various ways to solve problems, instead of an omniscient authority. Each study module must find its most appropriate and efficient learning/teaching methods.

Interdisciplinary, creativity, critical thinking and developed imagination must conclude the basis of the study programme. Students of various years and fields, as well as students of different modules must be encouraged to work together to find innovative ways to solve practical problems.

- The study programme implements the principle, based on good knowledge of the needs of the client and technological solutions - "Architectural form follows content". In this respect the programme in KTU is different from other programmes, in which the artistic architectural expression is the priority.

Adapting the architecture study program to the needs of nowadays, special attention has to be given to the integration of BIM in study process. BIM integration capabilities by $\mathbf{3}$ focus areas:

1. Integration to elective subjects;

2. The development of design based subjects;

3. Cooperation with praxis subjects (join project).

BIM implementation to the elective subjects based on software development. Students have possibilities to learn specific programs, which are integrated to the modules: CAD/CAM fabrication, 
WEB looping, parametric animation and installation, virtual reality generation and activation. BIM implementation to the design based subjects based on adaptation in speciality. Student can get basics about BIM process in architectural design subjects: architectural experiment, architectonic development, urban planning, research project and final degree project. And 3th focus area for BIM implementation to the Architecture study programme based on praxis subjects, especially join project. This multidisciplinary subject joins students with different specialities: architects, civil engineers, automatic engineers, urban engineers, building engineers and electrical engineers. Main aim of this subject: to provide a better understanding of the design process with BIM, learn to work in team and defend their professional interest in the project.

BIM Use

Opportunities In Master Studies

\section{Sustainable Architecture Programme of Norvegian Science And Technology University}

The MSc program in Sustainable Architecture at NTNU aims at educate and train building professionals in learning, using and developing competitive methods and solutions of bioclimatic architecture towards reduction of $\mathrm{GHG}$ emissions of the built environment. Learning outcomes of the program have been defined in accordance with the United Nations Framework Convention on Climate Change according to which greenhouse gas emissions concentration in the atmosphere should be significantly limited if we want to "prevent dangerous anthropogenic interference with the climate system". Scientific knowledge of different nature is used, throughout the two years of studies, as the platform for the architectural design of buildings characterized by low environmental impact. Cooperation between architects and engineers represents, in this regard, a fundamental key aspect. The program, moreover, is based on the assumption that multidisciplinary collaboration cannot be thought on a theoretical basis but can be learned only "learning by doing" through practical experiences. The program is therefore open to students with both background, architecture and engineer and they are usually balanced in number and nationality.

The curriculum of the MSc in Sustainable Architecture is structured around three main concerns related to the environmental impact of the built environment (climate and environmental performance of buildings; materials' durability and environmental impact; integrated energy design processes and energy systems). In each semester, students acquire specific knowledge and relevant competences for lowering GHG emissions of buildings. The first semester, based on a tight comparison between climatic data and human comfort requirements, focuses on passive bioclimatic strategies for energy efficiency and performance-driven design processes. The second semester

Fig. 4

Structure of the MSc program in Sustainable Architecture at NTNU

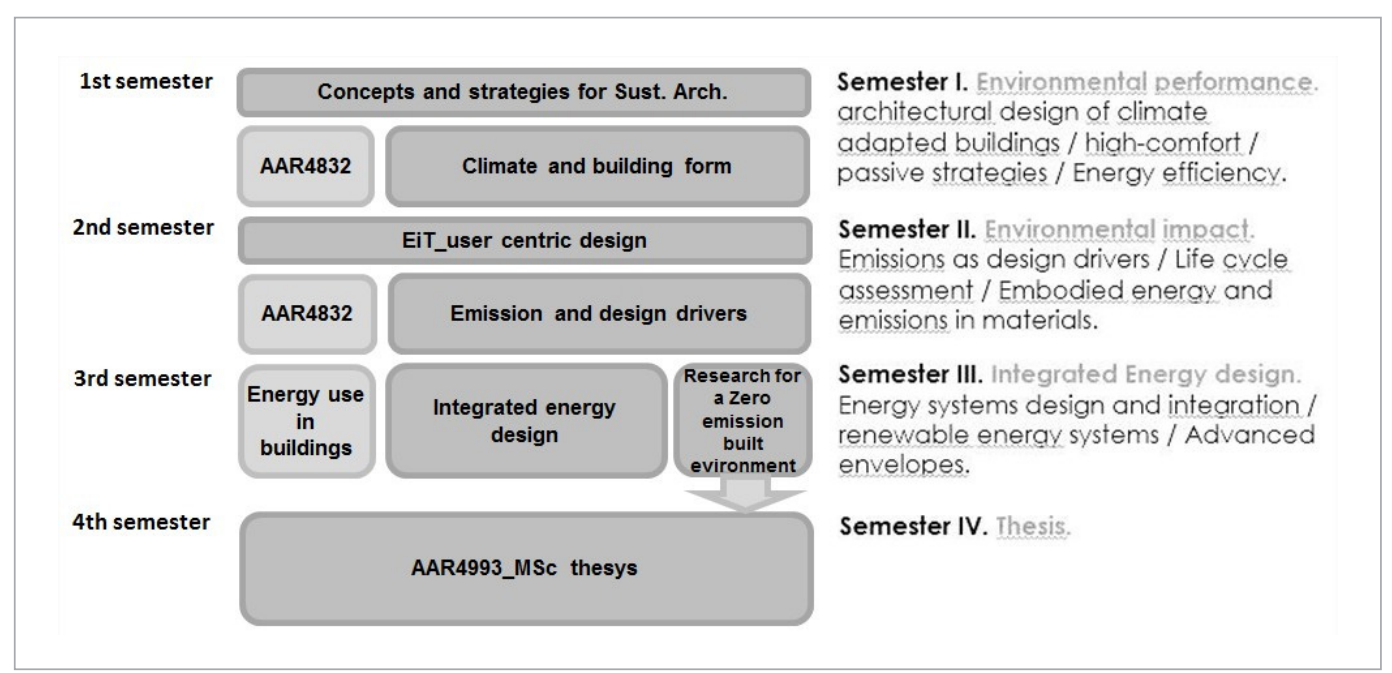


addresses issues related to the environmental impact of materials, their durability and understanding of buildings' life cycle. In that regard, students generally work with the transformation of an existing building. During the third semester, students are introduced to integrated energy design processes, relating environmental performance issues are to alternative energy systems, renewable energy systems' integration, and zero emission buildings targets [5].

The program accounts for a total of 120 ECTS and is divided, as all courses at NTNU, in modules of 7,5 ECTS. As for the whole Faculty of Architecture and Design, design courses account for 15 credits while theory courses account for 7,5 each. In every semester, a combined theory and design course - where a different theory package is meant to provide a scientific basis for the development of integrated design processes - accounts for a total of 22,5 credits. Design and theory courses, accounting for 15 and 7,5 credits respectively, are evaluated separately and on the basis of independent assignments. Remaining 7,5 credits per semester are used in the first semester for an introductory course on concepts and strategies for sustainable architecture, for multidisciplinary Experts in team course (run by NTNU in collaboration with all faculties) in the second and an elective course in the third one. Within each course, high demands are made towards the development of integrated solutions taking into account concerns related to users and environmental context. Interdisciplinary co-operation aims to let students explore the potential of integrated design methods and acquire valuable competences for their future praxis as building professionals. Students develop a 30 ECTS master thesis in the fourth and last semester. Theses are generally presented in the form of research reports, design projects or a combination of the two.

Besides students learn different kinds of digital tools during the program, no specific module about BIM has been implemented until today in the program. However, a first small attempt was done last year within the laboratory of the first semester in which a session of tutorial on how to create a simple BIM model in REVIT and export it in different simulations environments for conducting further energy analyses has been introduced. This session was ideated after having experienced of international students that in their background had the ability to model a building only in REVIT environment. Furthermore in several occasions, it has been discussed about the possibility of inserting a BIM module in the second semester, mostly for its potential for a fast accounting of materials and related emissions. This should facilitate design taking related to choice of materials and effort into minimizing the use of high-impact materials through optimization of number and dimensions of different elements (i.e. beams and columns as structure elements, dimension and number of openings, cladding elements etc.). A few students have developed their master thesis with the purpose of analysing the potential of BIM in emissions accounting and its current use in Norwegian companies. These works have been developed under the supervision of teachers responsible of the second semester.

\section{Using And Integrating the BIM Method in Different Study Cycles}

In order to find out the possibilities of using and integrating the BIM method in different study cycles, SWOT analysis was carried out in the following programs: Bsc Architectural Technology and Construction Management (Via University College), Integrated Studies Architecture (KTU), MSc Sustainable Architecture (NTNU) [6].

In all programmes was mentioned as a strength architecture connection with the civil engineering. BSC and Integrated studies (KTU and VIA university college) contains both architectural and engineering disciplines and MSc (NTNU) studies has a multidisciplinary nature: the program is open to both architects and engineers. That aspect gives the possibilities to introduce the BIM complex in a holistic way. One more strength was settled down in all programs: students are trained to use the digital tools and to implement it in different kind of design processes. By comparing the strengths of the programmes, it has been noted that there are no tuition fee in Danish and Norwegian higher

SWOT Analysis 


\begin{tabular}{|c|c|c|c|c|}
\hline \multirow{3}{*}{$\begin{array}{r}\text { Table } 1 \\
\text { scot/swot } \\
\text { Analysis example }\end{array}$} & \multicolumn{2}{|c|}{ Internal } & \multicolumn{2}{|c|}{ External } \\
\hline & Strengths & Challenges (Weaknesses) & Opportunities & Threats \\
\hline & $\begin{array}{l}\text { What's strong about } \\
\text { your study programme, } \\
\text { for example: BIM use } \\
\text { opportunities, education } \\
\text { and professional train- } \\
\text { ing, student projects, } \\
\text { software/equipment, } \\
\text { qualification of staff in } \\
\text { BIM projects, financial } \\
\text { support, staff training. }\end{array}$ & $\begin{array}{l}\text { What presents challenges, } \\
\text { such as: financial support, } \\
\text { short-staffed, space and } \\
\text { time limitations, software/ } \\
\text { equipment, staff training. } \\
\text { Note: Strengths can also be } \\
\text { weaknesses - a long-ten- } \\
\text { ured staff may have a lot of } \\
\text { experience, but they may } \\
\text { be too set in their ways, or } \\
\text { have stale ideas. }\end{array}$ & $\begin{array}{l}\text { Opportunities are the thing } \\
\text { your school/university has } \\
\text { no control over, but could } \\
\text { potentially take advantage } \\
\text { of. For example: grants, } \\
\text { partnerships, change in } \\
\text { demographics, etc. Try to } \\
\text { think outside of the box on } \\
\text { these. Your ability to see } \\
\text { opportunities coming could } \\
\text { be significant. }\end{array}$ & $\begin{array}{l}\text { What external threats } \\
\text { exist that could harm } \\
\text { BIM using/integration } \\
\text { in study programme? } \\
\text { Some examples: the } \\
\text { economic downturn, } \\
\text { elimination of funding, } \\
\text { university policy chang- } \\
\text { es, etc. }\end{array}$ \\
\hline
\end{tabular}

education institutions, while 70\% Lithuanian students and 100\% international students in Lithuania pay a tuition fee and it is the weakness of the programme. One more of the strengths of the studied programmes is the available or planned equipment, which students can use for their studies. This strength was mentioned in the analysis of BSc and Integrated studies programs: Via for 5 years has BIM laboratory, while KTU expects to open the Smart Cities and Infrastructure Center into 2019. NTNU has a BIM laboratory at the Faculty of Engineering in Trondheim and a well-established research group in NTNU Gjøvik. Recently, the Faculty of Architecture and Design at NTNU declared BIM as an area for strategic development within the Institute of Architecture and Planning. Few of the most important strengths were mentioned of all three countries: close collaboration with researchers' community, staff training in the field of BIM. Besides KTU mentioned students participation in international/national competitions, where students are implementing BIM in their projects and NTNU mentioned possibility of developing a thesis based on BIM knowledge and/or practice coupled with professional training in companies' leaders in the BIM sector.

The fact that the BSc program contains both architectural and engineering disciplines gives possibilities. However, this strength has also a weakness imbedded. In the multidisciplinary content of the program, the engineering disciplines are described but the actual 3D engineering models (structural and HVAC) are missing, That gives a less understanding and since the students are making individual projects, it is impossible for the engineering lecture staff to serve all students with individual models. All universities in their programs analysis noticed that there is a lack of BIM competencies in lecturer staff and in KTU highlighted big business of teaching staff. Despite many calls for developing individual competences among the teachers' staff, there is still reluctance to develop the necessary skills. KTU also highlighted the lack of student motivation, which was not mentioned by the other two schools. Most likely, this is related to paid studies in Lithuania, which results in less students focusing on studies and more on job. In addition, student's motivation to use BIM is reducing after students returns from Internship in the industry or in the architectural company, some of them experienced only a very limited use of BIM implementation. This weakness was mentioned in two programs - Bsc and Integrated studies. One more weakness of the programs was common for two HEl (KTU and NTNU) - the focus on integrated design processes represents a quality of the program but it is often challenging to ensure architectural quality in all the design projects. One special strength was setted down as also as challenge in NTNU - diversity among students is generally reflected in different expectations, learning methods and experiences. This generally represent a richness of the program but can also be a challenge when defining teaching methodology and contents fulfilling different expectations, especially that there is a lack of a dedicated module, laboratory and/or course of BIM in the Msc program in Sustainable Architecture. 
As one of the opportunities, in all programs SWOT analysis was mentioned the opportunity to establish cross-disciplinary cooperation among the different faculties or with different universities in the international level to run "a real BIM-project" with all the respective disciplines involved with fully supplied discipline-models. One opportunity was settled dawn by KTU, also could be treated as a threat - from the 1st of July 2022 - will become compulsory to use BIM methods for the design and construction of all newly constructed complex and high value public sector buildings, but Architects' Chamber of Lithuania (a professional self-governing organization of certified architects) opposes mandatory introduction of BIM, because that the Lithuanian market is not ready for it and any forced application of technology is to be considered only as an attempt to restrict competition. Architects' Chamber of Lithuania is afraid of that the consequence of this design is probably the multiplication of typical buildings. Therefore, in one hand this new law could be as an opportunity for adaptation BIM into high education, because of strengthening the competences of digitalization of architecture students and increased involvement of students in international projects and opportunities for internships abroad, but in other hand as a threat, because Architects' Chamber of Lithuania is against it. VIA University College, see the opportunity of development of the educational BIM-Lab. In BIM lab there should be opportunities to develop solid BIM-projects where participation should be determinated by the educational discipline (Arch - Struc - HVAC) and NTNU, see the opportunity of out of the LAB into the City: organize visit on site for showing BIM potentialities in construction management or visit in factories/great firms for BIM design.

Understanding of architecture as use of standard commercially available components limiting freedom and creativeness in the design process was settled down not only in KTU SWOT Analysis, but also in NTNU. VIA University College mentioned that greater savings in education could also affect the overall focus on BIM implementation. In the coming 3 years the program suffer from an annual savings. Changes in legislation and policy of the KTU and the Ministry of Education and Science, influencing the instability of the study program in KTU. Permanent change causes the demotivation of academic staff, and it will not be desirable to work with new methods. NTNU mentioned special threats, which are connected with their program: the largest concern is that of shifting too much the focus of the program from environmental impact analyses and sustainability concerns into construction and management. Introducing BIM might further increase complexity within the design process, resulting in lower attention towards sustainability concern. One more threat was mentioned by VIA University College - the lack of use of the IFC - format in the industry, which means small support from the industry and also from the government.

A student survey was conducted to find out students' opinions and knowledge about BIM. The aim of this survey was to find out how they understand the BIM term, which software's they learned during the studies and etc. Their experience will help to improve BIM teaching methods in the Architecture program.

In the survey participated: 21 Architecture program students from KTU (18 BSc level students (19 - 8 semester and 2 - 6 semester) and 3 MSc students); 19 MSc level Sustainable architecture program students from NTNU and 80 BSc level Architectural Technology and Construction Management students from VIA (50 Danish students and 30 international students). NTNU students are with different background: $86 \%$ have BSc diploma in Architecture, $10 \%$ - Building engineering and $4 \%$ - other.

To the question "How do you understand what is BIM (Building Information Modelling)" $48 \%$ of KTU students, $20 \%$ VIA students and $28 \%$ NTNU students answered that BIM is digital processing and simulation of geometric and physical data in a construction process and subsequent operational phase; that BIM is Process, which covers the whole life-cycle of the building answered $14 \%$ of

\section{Student's Opinion Survey About BIM}


NTNU students, $29 \%$ of VIA students and $10 \%$ KTU students. $29 \%$ VIA students and $28 \%$ NTNU students answered that BIM is digitization of construction and building operations, while just $10 \%$ of KTU students picked this answer. Biggest part of respondents understand BIM meaning right.

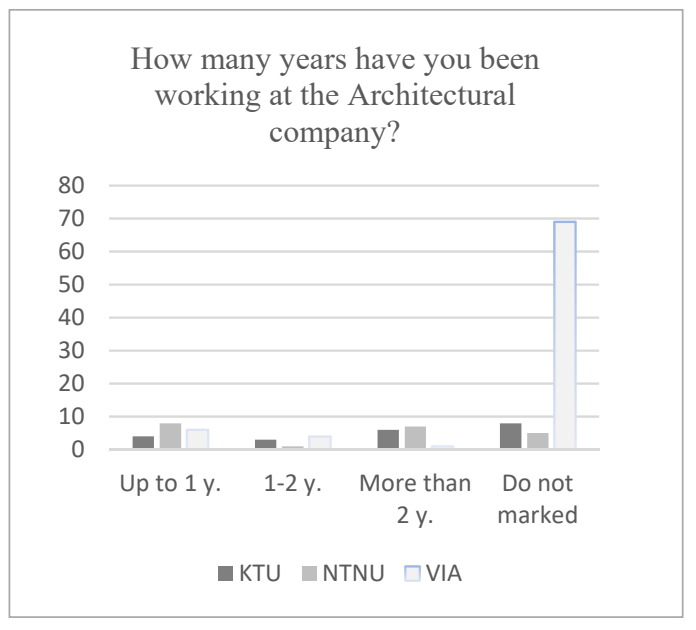
show that $53 \%$ architectural companies, where NTNU students are working, are using BIM. 2/3 of VIA respondents said that their company use BIM.

From the survey, we can do the conclusion that mostly architectural companies work with Auto Cad and/or Revit. That shows that the architectural environment is to a certain degree prepared for the BIM but they do not need this method because there are not a certain need from the customers also based on the legislation of research countries.

It was interesting to find out which software's KTU, VIA and NTNU students learned during the studies and compare their knowledge's with what they need, therefore was given the question "What software's did you learn to use during your studies?" To this question were asked to answer all respondents. Results shows that $100 \%$ of respondents from KTU learned to use AutoCAD and just $29 \%$ Revit. These two software's are taught in KTU Architecture programme. Comparing the VIA situation, we see opposite results - $100 \%$ of students learned Revit, because it is the overall chosen software in the programme, and Sketch Up with $38 \%$, because it is taught in the international programme. NTNU survey shows, that 38\% respondents learned Revit, $19 \%$ AutoCAD during their studies.

Some of respondents wrote other software's, which they learned during the study years: Photoshop, CorelDraw, Rhinoceros, Grasshopper and Kangaroo Physics. From the software's, which

What software did you learn to use during your studies?

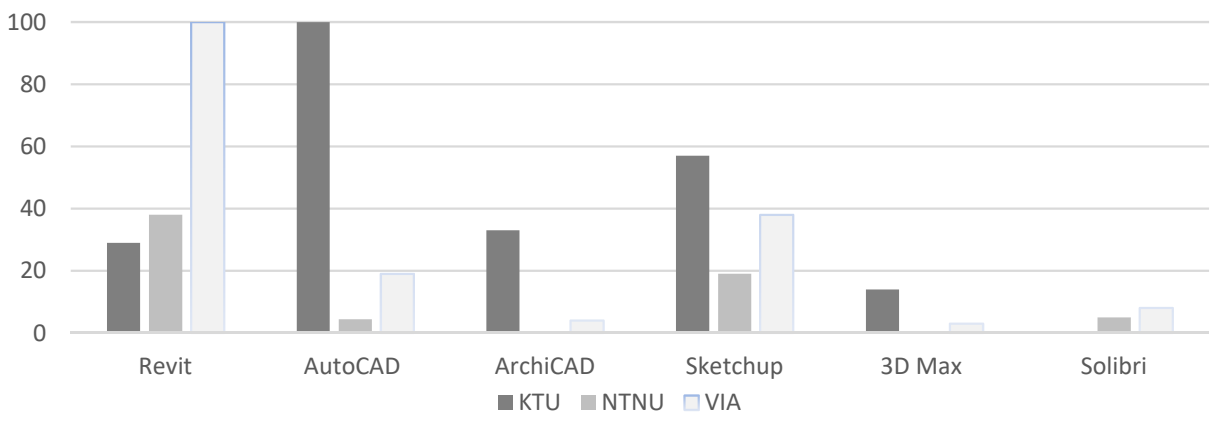


students learned, we can do the conclusion that majority of programs are used for visualizations and design creation.

Majority of respondents think that it is important for the architect to be able work in the BIM method: KTU - $57 \%$ (very important) and $19 \%$ (important); VIA - $38 \%$ (very important) and 46 $\%$ (important); NTNU - $29 \%$ (very important) and $48 \%$ (important). Majority of respondents are very much interested: KTU - $48 \%$, VIA - $28 \%$, NTNU - $15 \%$ or interested: KTU - $28 \%$, VIA - $40 \%$, NTNU - $54 \%$, into BIM modelling.

In this survey, respondents were asked to answer to few open questions. To the question, "Which characteristics and potentialities of BIM are you mostly interested in?" respondents mentioned: 3D models creation; connecting the same model with different parts of the project; cooperation between different specialists; an opportunity to edit the project and see the changes very fast in all parts of the project; the concept of open data and interaction between different software; quick estimate preparation; data sheets; project management.

To the question, "What skills should you gain during architectural studies that enables you to work on the BIM method?" respondents mentioned 3D models, quick estimate preparation; data sheets; ability to work with different software; Revit, making schedules

Majority respondents answered to the final open question, "In which semester should be integrated course how to use BIM method?", that integration of BIM should start from the first semester and to be used in all studies.

In VIA College, Denmark, the progression of BIM uses through the Constructing Architect courses' semesters happens via 5 focus areas:

1. Basic modelling and extraction from drawings;

2. Quantity take-offs;

3. Utilization of the properties data, incl. establishment of own properties data;

4. Visualization;

5. Integration with other software applications (hereafter called programs).

In KTU Architectural study programme progression of BIM uses going by 3 main focus areas:

1. Integration to elective subjects;

Model for Integration of the International BIM Project In Different Study Cycles

2. the development of design based subjects;

3. Cooperation with praxis subjects (join project).
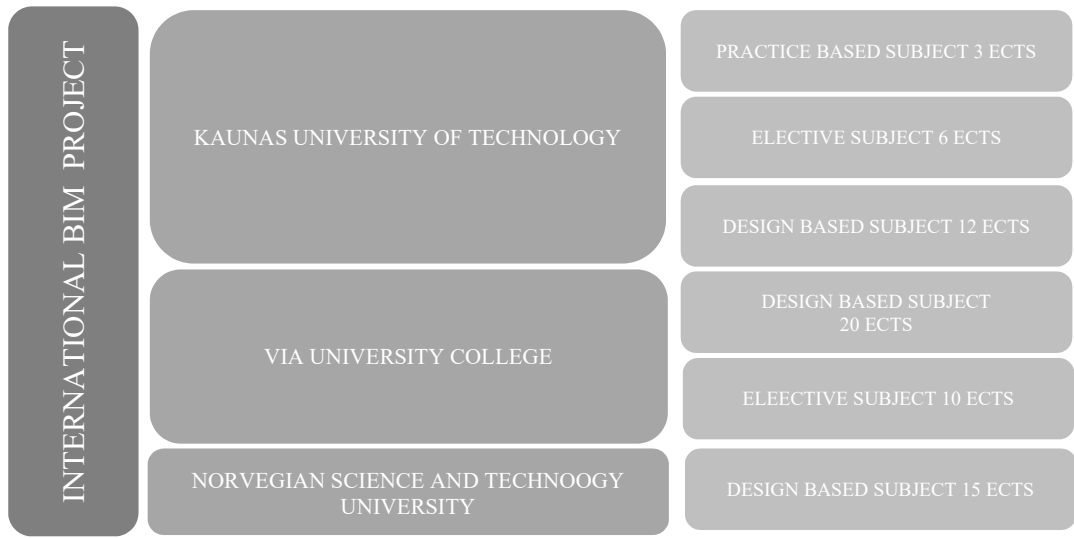

5th semester

6th semester

5th semester

4th semester

5th semester

1 st semester

\section{Fig. 5}

Structure of integration of the international BIM project in different study cycles 
In NTNU Sustainable Architecture study programme a first attempt was done in the laboratory of the first semester in which a session of tutorial on how to create a simple BIM model in REVIT and export it in different simulations environments for conducting further energy analyses has been introduced.

\section{Conclusions}

In SWOT analysis was find out that in Bsc Architectural Technology and Construction Management (Via University College), Integrated Studies Architecture (KTU), MSc Sustainable Architecture (NTNU) programmes was mentioned as the strengths: architecture connection with the civil engineering; in VIA and NTNU there are no tuition fee, while $70 \%$ Lithuanian students and $100 \%$ international students in Lithuania pay a tuition fee and it is the weakness of the Lithuanian programme; close collaboration with researchers' community, staff training in the field of BIM.

- All universities in their programs SWOT analysis noticed that there is a lack of BIM competencies in lecturer staff and in KTU highlighted big business of teaching staff and the lack of student motivation, which was not mentioned by the other two schools.

As one of the opportunities, in all programs SWOT analysis was mentioned the opportunity to establish cross-disciplinary cooperation among the different faculties or with different universities in the international level to run "a real BIM-project" with all the respective disciplines involved with fully supplied discipline-models.

- Understanding of architecture as use of standard commercially available components limiting freedom and creativeness in the design process was settled down in KTU and NTNU SWOT analysis. As special weakness was mention just in KTU SWOT analysis: permanent changes in legislation and policy of the KTU and the Ministry of Education and Science causes the demotivation of academic staff, and it will not be desirable to work with new methods.

- In the students survey participated 120 students (21 KTU, 19 NTNU, 80 VIA). In the survey was find out that biggest part of students from all countries understand BIM meaning; the possibilities which this method is giving, but face with the problem, that BIM is not very popular between architectural companies as architectural environment is just to a certain degree prepared for the BIM and they do not need this method because there are not a certain need from the customers also based on the legislation of all countries.

\section{References}

"Nordplus" projekto pagalba Statybos ir architektūros fakultete tobulinamos studijų programos: https://saf.ktu.edu/news/nordplus-projekto-pagalba-statybos-ir-architekturos-fakultete-tobulinamos-studiju-programos/, 2017-09-07.

Project execution planning guide-v2.0: BIM Project Execution Planning Guide, 2018-06-20.

IA University College, Architectural Technology \& Construction Management study programme: https:// en.via.dk/programmes/technology-and-construction/architectural-technology-bachelor , 2018-06-20.
Kaunas University of Technology, Architecture study programme: https://admissions.ktu.edu/?study-program=v-architecture, 2018-06-20.

Norvegian Science And Technoogy University, Sustainable Architecture study programme: https:// www.ntnu.edu/studies/mssusarc, 2018-06-20.

The researchers of the KTU SAF, together with colleagues from the Nordic countries, examined BIM prospects in studies: https://fcea.ktu.edu/news/ the-researchers-of-the-ktu-saf-together-withcolleagues-from-the-nordic-countries-examinedbim-prospects-in-studies/, 2018-10-22. 


\section{AUŠRA MLINKAUSKIENĖ}

Associate Professor

Kaunas University of Technology, Faculty of Civil Engineering and Architecture

\section{Main research area}

Cultural heritage, protected areas, cultural landscapes, urban structures.

\section{Address}

Studentu st. 48, LT-51367

Kaunas, Lithuania

Tel. +370 300450

E-mail: ausra.mlinkauskiene@ktu.lt.

\section{LUCA FINOCCHIARO}

Associate Professor

Norwegian University of Science and Technology, Department of Architecture and Technology

\section{Main research area}

Architectural design, climate changes, zero emission buildings, sustainable architecture.

\section{Address}

Alfred Getz vei 3 _ NO 7491

Trondheim

E-mail: luca.finocchiaro@ntnu.no

\section{LAURA JANKAUSKAITĖ-} JUREVIČIENĖ

\section{Lecturer}

Kaunas University of

Technology, Faculty of Civil

Engineering and Architecture

Main research area

Cultural heritage, architectura design, HBIM, parametric architecture.

\section{Address}

Studentu st. 48, LT-51367

Kaunas, Lithuania

Tel. +370300450

E-mail: laura.jankauskaitejureviciene@ktu.lt

\section{GABRIELE LOBACCARO}

\section{Researcher}

Norwegian University of Science and Technology, Department of Architecture and Technology

\section{Main research area}

Environmental engineering, climate models, urban planning, sustainable architecture, building physics.

\section{Address}

Alfred Getz vei 3 _ NO 7491

Trondheim

E-mail: gabriele.lobaccaro@ntnu.no

\section{PER CHRISTENSEN}

Lecturer - BIM coordinator Master of ICT and Learning

VIA Architectural Technology and Construction Management

\section{Main research area}

BIM processes and legislation - CSCL Computer supported collaborative learning.

Address

Chr. M. Østergaards Vej 4, DK - 8700 Horsens Tel. +4587554000

E-mail: pc@via.dk
About the Authors 